\title{
Desain Karakter dan Kostum khas Indonesia "TRAVELION"
}

\author{
Ade Josafat Chrisdianto dan Andhika Estiyono \\ Departemen Desain Produk Industri, Fakultas Teknik Sipil dan Perencanaan, Institut Teknologi Sepuluh \\ Nopember (ITS) \\ e-mail: andhika@prodes.its.ac.id
}

\begin{abstract}
Abstrak-Karakter Super hero di Indonesia mulai digemari dan banyak peminatnya, akan tetapi karakter yang dibuat bukalah dari karakter asli dari Indonesia sendiri, melainkan dari Negara lagi, seperti Amerika dan Jepang,sehingga peneliti mencoba mengusung karakter dengan tema Indonesia tersebut dengan mengemasnya dalam bentuk kostum sehingga kearifan lokal Indonesia dapat hidup kembali, dan digemari oleh masyarakat saat ini, dengan cara mendesain Karakter dan kostum khas Indonesia.Adapun metode yang dilakukan adalah dengan cara mengukur, menimbang, dan mengamati karakter yang sudah ada di pasaran. Kemudian menggabungkan beberapa sambungan dari karakter yang sudah ada kemudian menyederhanakannya.Studi yang dilakukan oleh peneliti diantaranya Deep interview,analisis model,desain rangka,analisis material,branding,packaging,analisis rencana anggaran biaya ( produksi masal ), rencana bisnis, dan analisa karakter wajah Indonesia,dari laporan ini peneliti mendapatkan kesimpulan bahwa Desain kostum dengan tema khas Indonesia memiliki pasar tersendiri, yang saat ini belum cukup banyak, namun kesempatan dalam industri ini cukup besar, dikarenakan sedikitnya competitor yang bermain dibidang ini.
\end{abstract}

Kata Kunci-Kostum, Travelion.

\section{PENDAHULUAN}

$\mathrm{C}$ OSPLAY adalah hobi baru yang mulai menyebar di hampir seluruh indonesia, hobi ini berawal dari negara Jepang dan Amerika. Cosplay adalah seni bermain peran sesuai dengan karakter yang ada dari Anime,Game, dan Tokusatsu. Hobby ini lahir di Jepang pada tahun 1990, dan mulai menyebar ke asia tenggara, di Indonesia sendiri cosplay mulai berkembang pesat pada tahun 2004. berawal dari acara bunkasai (festival jepang) kampus-kampus sampai acara toy festival di mall, cosplay juga mempunyai 3 macam, yaitu cosplay armor, cosplay semiarmor dan cosplay fabric. Hal ini sering di perlombakan di eventevent tertentu. Karakteryang banyak di cosplay kan di Indonesia yaitu dari anime dan tokusatsu. Mereka juga dari kalangan pelajar sampai pekerja. Lebih banyak mereka membeli dari penjual kostum untuk dipakai ke event. Tidak sedikit peminat cosplay di Indonesia ini terutama di surabaya. Mereka rela membeli kostum dengan harga yang sangat mahal untuk mendapatkan kualitas yang bagus. Terutama cosplayer tokusatsu, mereka dari anak kecil sampai orang yang sudah berumah tangga. Tokusatsu dalam dunia cosplay termasuk dalam cosplay armor. Seringnya event yang berhubungan dengan cosplay, sering juga peminat cosplay juga, dan banyak pula yang ingin membuat kostum. Dari awal mereka akan kebingungan untuk mencari cara untuk membuatnya. Dan pada akhirnya mereka akan menemukan kostum maker dan menggunakan jasanya. Dan biasanya pembuatan kostum itu minimal pembuatan 30 hari. Dan itu juga kadang kurang tepat waktu, serta ukuran ukuran yang harus pas, dan juga biasanya mereka membeli di online shop. Biasanya ukuran yang mereka berikan kurang pas, serta mereka mempunyai masalah dalam packaging.

Di masa sosial media ini banyak sekali berita berita atau entertaiment yang membuat orang orang mau untuk berlama lama di depan laptop atau handphone nya. Contohnya Facebook, Twitter, Tumblr, Path dan tak terkecuali Web toon/ komik komik online. Dan rata rata orang orang juga suka berlama lama untuk membaca komik online yang notaben nya itu gratis dan bisa dibaca siapa saja. Dan juga tidak banyak, setelah orang tersebut membaca dan langsung ingin menjadikan project cosplay nya, biasanya di pengaruhi faktor karakter yang bagus, lucu, ikonik dan cerita yang bagus juga pastinya. Dan dari situlah awal mula para cosplayer menggemari karakter yang dia suka.

\section{A. Apa itu kostum?}

Kostum tidak hanya memainkan peran yang sangat penting dalam seni pertunjukan, tapi juga begitu signifikan dalam kehidupan kita sehari-hari. Apa yang Anda pilih untuk dipakai dan kapan bisa dipakai untuk Keluarga. dan teman-teman dengan banyak rincian tentang suasana hati Anda atau ke mana Anda pergi. Pilihan ini tentukan bagaimana kita menampilkan diri kita kepada dunia. Entah itu pakaian luar, pakaian olahraga, atau kombinasi yang unik, pakaian kami membuat pernyataan tentang siapa kami atau inginkan,dan bagaimana kita ingin dunia memandang kita. Kostum yang bagus bisa memberi tahu penonton tentang sifat karakter sebelum sebuah kata telah diucapkan[1]. 


\section{B. Membuat Kostum baik untuk Anda}

Hal yang paling penting bagi seseorang untuk tampil bagus dalam kostum adalah mereka harus melakukannya merasa nyaman di dalamnya, saran Tanisa. Dengan ini dia berarti kenyamanan fisik, Kostumnya kokoh dan tidak berantakan di sekeliling pemakainya. Tapi dia juga menjelaskan bahwa kain nya

sedikit lebih halus. Orang mungkin membayangkan bahwa seorang pelanggan profesional mungkin akan menghabiskannya. Sebagian besar waktunya dengan lembut berbicara dengan orang-orang yang tidak sesuai dengan usia.

Namun, rupanya sudah umum orang mengira mereka tidak tampan cukup untuk menarik dari tampilan tertentu. Orang harus "menurunkan penjaga mereka" untuk memakai Kostum secara efektif, Tanisa mengatakan, dan tidak semua orang bisa atau akan melakukan itu. Dan mereka harus melakukannya "Putuskan jenis perhatian apa yang ingin mereka dapatkan."[1].

\section{METODOLOGI}

\section{A. User Interview}

User Interview dilakukan pada acara cosplay, acara yang paling besar adalah "CLAS:H" di Surabaya.pada tanggal 26 Maret 2017 di DBL Arena Surabaya,dengan saya sendiri menjadi juri di acara tersebut, saya bisa menilai hampir semua cosplayer yang ada di acara, adapun beberapa hal yang saya pelajari yaitu :

\section{1) Ruang gerak}

Para cosplayer tidak bisa bergerak dengan bebas se maksimal mungkin, jadi mereka hanya bergerak sampai pada batasnya.

\section{2) Kostum yang berat}

Dikarenakan mereka memakai material yang berat, maka mereka akan terhalang untuk bergerak karena berat dari kostum tersebut.

\section{3) Hawa yang panas}

Kostum yang mereka pakai tidak menyerap udara, sehingga tidak ada udara yang masuk untuk memberi napas bagi mereka. 4) Kostum dibuat sendiri

Kostum yang mereka buat, kebanyakan dibuat sendiri dan memakan banyak waktu seperti satu kostum dibuat 1 bulan minimal, dan ada juga yang 2-3 bulan pembuatan.

\section{B. Survey}

Ada pun di mana saya melakukan survey untuk mencari peminat para super hero dari karakter yang akan saya ambil.Survey yang saya maksud mengacu pada pertanyaan tentang super hero Indonesia. Hasilnya adalah 188 hasil survey yang mengacu pada desain yang memberikan pada super hero dengan kearifan lokal Indonesia.

\section{Analisa detail kostum}

Bahwa desain kostum berawal dari desain yang sudah ada dan di olah lagi menjadi kostum yang baru, dari segi garis, bentuk, warna, image, dan unsur bentuk, setelah di analisa, maka hal selanjutnya adalah menjelaskan detail dari bentuk yang kita pilih menjadi hal yang baru.

\section{Affinity Diagram}

Metode yang digunakan untuk mengelompokan masalah yang ada dari fenomena - fenomena yang disimpulkan dari pengumpulan dan analisa data sebelumnya.

\section{E. Eksplorasi Ide}

Sketsa dan brainstorming menjadikan hasil dari data primer dan sekunder disatukan kemudian diproses kembali melewati sketsa - sketsa kasar yang menghasilkan ide baru.

\section{F. Pemilihan desain alternatif}

Hasil dari pemilihan ide dipilih dan dikerucutkan menjadi desain alternatif yang sesuai dengan indikator yang pas berdasarkan hasil riset dan desain.

\section{G. Studi dan analisa desain}

Alternatif yang terpilih akan dikembangkan menjadi lebih detail dengan di bantu oleh riset - riset yang telah dilakukan sebelumnya yang disesuaikan dengan aspek teknis, bentuk, dan semacamnya.

\section{H. Pengembangan desain}

\section{1) Studi Model}

Studi selanjutnya membuat model untuk menemukan bentuk serta fungsi teknis yang cocok dan dapat disatukan dengan desain as li nya nanti dan menentukan bertuk yang cocok jika di perbesarkan.

2) Digital Modeling

Desain yang terpilih di simulasi kan secara digital untuk mempermudah mendapatkan alternatif yang baik

\section{Prototyping}

Final desain yang dipilih direalisasikan dengan wujud aslinya berskala 1:1 dengan menggunakan 90\% dari material aslinya.

\section{J. 10.Usability test}

Tahap akhir adalah percobaan prototype yang digunakan pada user as linya baik target maupun pengganti user.

\section{KONSEP DAN ANALISA}

\section{A. Konsep desain}

Ide dan eksperimen telah dilakukan dan diproses untuk menemukan konsep desain melalui brainstorming, seperti berikut : 


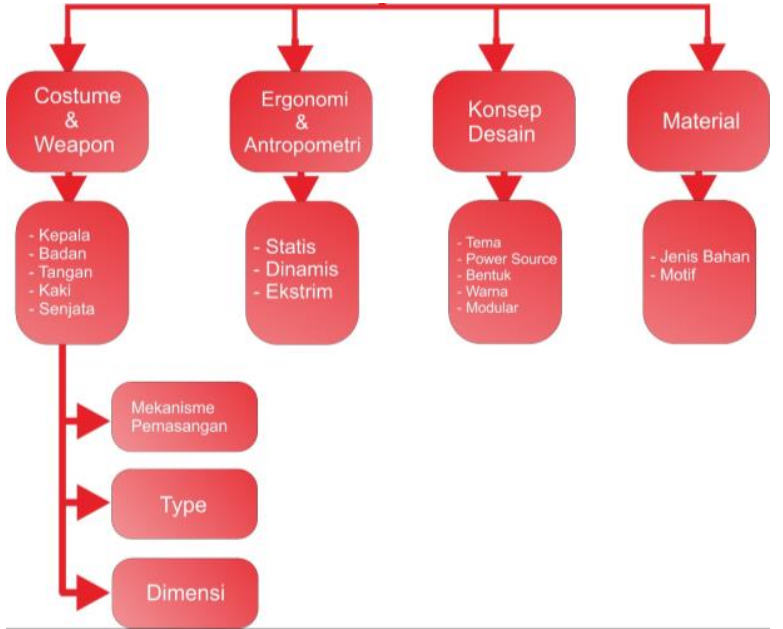

Gambar 2. Skema Brainstorming konsep.

Dari hasil brainstorming diatas memunculkan 3 kata kunci pada konsep desain meliputi :

1) Kostum dan Senjata

Menjelaskan part dari sebuah kostum yang akan di gunakan dan mekanisme didalamnya.

2) Ergonomi dan Antropometri

Menjelaskan bahwa harus mempunyai ukuran dalam menggunakan kostum tersebut

3) Konsep desain

Menjelaskan tentang detail ornamen,bentuk, warna dan tema dari sebuah kostum tersebut.

4) Material

Menjelaskan bahwa material apa saja yang akan digunakan dalam membuat kostum.

\section{B. Analisa Kostum}

Analisa kostum yang akan di desain ini memiliki penjelasan tersendiri dari tiap part dari bagian tubuhnya.

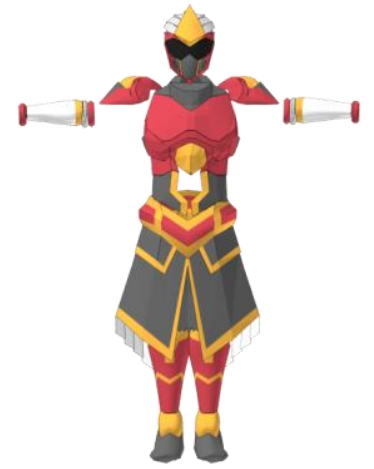

Gambar 3. Semua Part Desain dari Kostum Travelion

\section{Ergonomi dan Antropometri}

1. Helmet: sejenis pelindung kepala serta menjadi icon dari sebuah kostum dan juga mempresentasikan bentuk dari form yang ada di kostum tersebut

2. Breastplate : bagian pelindung dada dan punggung, part ini sangat penting untuk semua kostum jenis tokusatsu, selain digunakan menjadi pelindung, part ini juga menjadi icon untuk mempresentasikan bentuk form yang ada di kostum sama halnya dengan helmet.

3. Pauldron : bagian ini adalah pelindung untuk bahu. Akan tetapi bagian ini adalah sebuah pemanis untuk kostum seri tokusatsu, bagian ini membuat keseluruhan bagian tubuh terlihat kuat dan besar layaknya super hero.

4. Bracer dan Shin Armor: adalah bagian pelindung tangan dan kaki yang ada di bagian dari kostum tokusatsu. Biasanya dipakai juga untuk alat berubah yang ada di tangan dan alat untuk mengerluarkan kekuatan dan jurus di bagian kaki.

5. Belt: bagian sabuk ini adalah bagian paling penting juga di kostum tokusatsu, karena part ini adalah power sourceatau alat berubah. Biasanya dipakai juga untuk mengeluarkan kekuatan atau merubah form yang lain.

\section{Material}

Definisi beberapa material yang saya pakai disini adalah material yang ramah dan ringan terhadap tubuh konsumen. Dan tidak mengganggu pergerakan jika dipakai atau di lakukan dalam perform.

\section{HASIL DAN PEMBAHASAN}

\section{A. Desain Akhir}

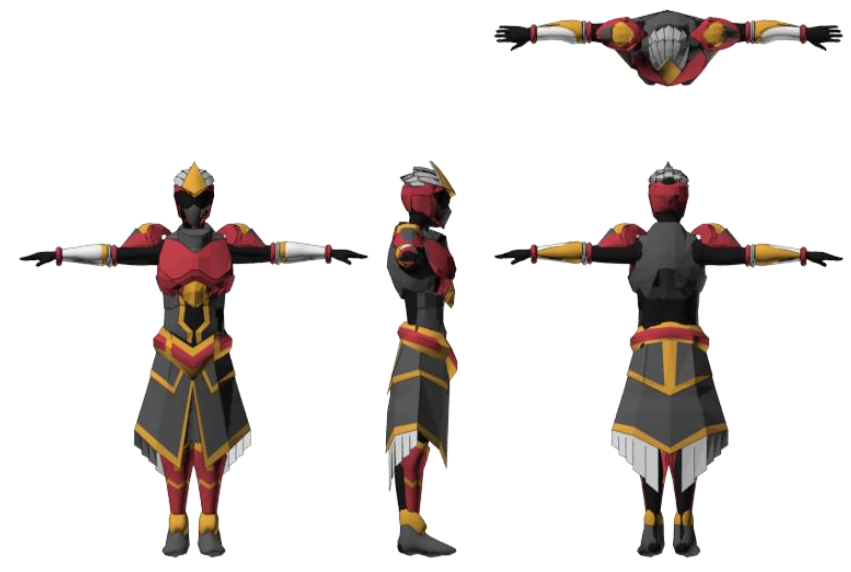

Gambar 5. Hasil Render gambar tampak dari Travelion.

Hasil dari analis a data dari awal hingga diruncingkan lagi menjadi hasil yang seperti ini. 


\section{B. Gambar Urai}

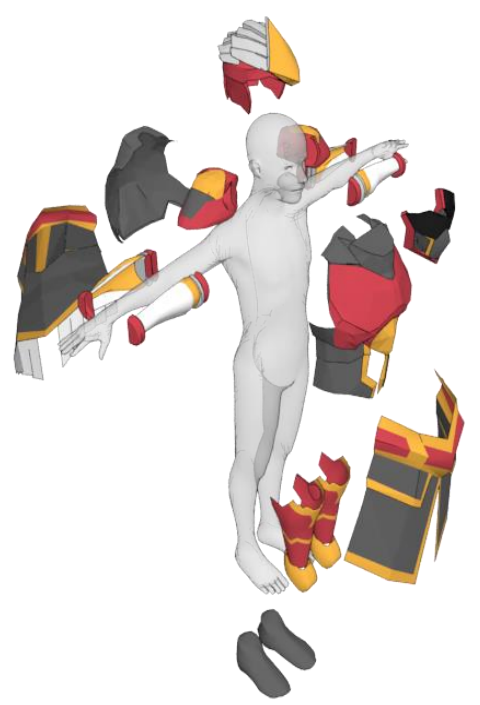

Gambar 6. Uraian dari part kostum Travelion.

Hasil uraian ini menjelaskan bahwa akan di buat joining untuk memasang kostum tersebut ke badan pemakai.
C. Prototyping

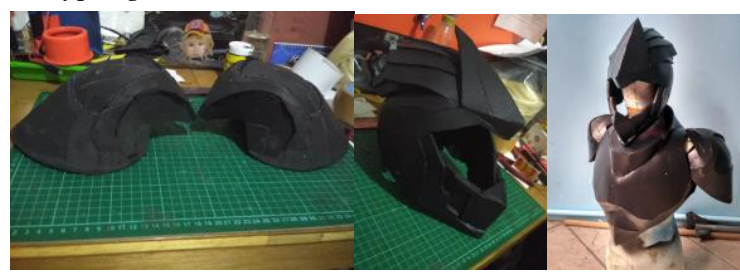

Gambar 7. Hasil Progres dari kostum travelion.

\section{KESIMPULAN/RINGKASAN}

Dalam merancang karakter dan kostum selain aspek kostum itu sendiri perlu diperhatikan dalam pembuatan karakter agar memicu peminat untuk mengetahui latar belakang dari Travelion tersebut. Material serta finishing produk akhir yang digunakan oleh seluruh komponen juga tidak membahayakan User karena target pasar tidak hanya untuk dewasa saja, melainkan juga untuk anak kecil.

\section{DAFTAR PUSTAKA}

[1] P. F. Tech, Wearable Technologies for Costuming, Cosplay, and Everyday. Apress, 2016. 